\title{
Envejecimiento y atención a la dependencia en los territorios de Euskal Herria
}

\author{
Arrate Arin \\ Eusko Ikaskuntza \\ arrate.arin@eusko-ikaskuntza.eus
}

\section{Maia Berasategui \\ Etcharry Formation Développement}

\section{Lucía Martínez Virto}

Universidad Pública de Navarra

\section{Laurent Melito}

Etcharry Formation Développement

\author{
Ángel Toña \\ Eusko lkaskuntza

\section{Joseba Zalakain} \\ SIIS Servicio de Información e Investigación Social
}

\begin{abstract}
Artikulu honek Gipuzkoako Foru Aldundiko Gizarte Politikako Departamentuak Euskal Autonomia Erkidegoan, Nafarroako Foru Erkidegoan eta Ipar Euskal Herrian mendekotasun-egoeran dauden pertsona adinduei ematen zaien artaren inguruan finantzatutako txosten bat laburbiltzen du. Lan honen helburua hirukoitza da. Alde batetik, lurralde bakoitzeko pertsona adinduen edo mendekotasunegoeran dauden pertsonentzako gizartezerbitzuen sistemaren oinarrizko funtzionamendua deskribatzea. Bestetik, politika horiek lurralde bakoitzean duten irismen-dimentsioa neurtu eta erlazionatzea ahalbidetuko duten datuak eta adierazleak aurkeztea; artatutako pertsonen kopuruaren, eskainitako zerbitzuen, okupatutako langileen edo egindako gastuaren ikuspegitik. Azkenik, hiru lurraldeen artean dauden antzekotasun eta desadostasun nagusiak identifikatzea; erronka komunak identifikatzea -baita lurralde bakoitzeko berariazko erronkak ere-; eta, lortutako ikaskuntzetatik abiatuta, aztergai hartutako hiru lurraldeen zerbitzuak hobetzeko zenbait gomendio proposatu.
\end{abstract}

\section{GAKO-HITZAK:}

Pertsona adinduak, mendekotasuna, gizartezerbitzuak, datu estatistikoak, gomendioak, Euskal Herria.
Este artículo resume un informe financiado por el Departamento de Política Social de la Diputación Foral de Gipuzkoa sobre la atención a las personas mayores dependientes en la Comunidad Autónoma Vasca, la Comunidad Foral Navarra e Ipar Euskal Herria. El objetivo del trabajo es triple. Por una parte, describir el funcionamiento básico del sistema de servicios sociales para personas mayores 0 dependientes en cada territorio. Por otra, ofrecer datos e indicadores que permitan dimensionar y poner en relación el alcance de esas políticas en cada territorio, desde el punto de vista del número de personas atendidas, los servicios ofrecidos, el personal ocupado o el gasto realizado. Por último, identificar las principales similitudes y divergencias que existen entre los tres territorios, identificar los retos comunes - así como los específicos de cada territorio- y plantear algunas recomendaciones para la mejora de los servicios en los tres territorios analizados, a partir de los aprendizajes extraídos.

\section{Palabras Clave:}

Personas mayores, dependencia, servicios sociales, datos estadísticos, recomendaciones, Euskal Herria. 


\section{Introducción}

En el espacio geográfico conformado por la Comunidad Autónoma Vasca (CAV), la Comunidad Foral Navarra e Ipar Euskal Herria encontramos tres modelos muy diferentes de bienestar social, con diferentes concepciones políticas y niveles competenciales. Aunque las necesidades y riesgos sociales son similares, la respuesta que tradicionalmente se ha dado a esas necesidades ha sido muy diferente en cada una de las tres áreas. El territorio transfronterizo constituye en ese sentido un espacio de reflexión estratégico y un laboratorio del cual pueden extraerse análisis, aprendizajes e innovaciones de gran interés para la mejora de las políticas de intervención social.

Este artículo resume un informe financiado por el Departamento de Política Social de la Diputación Foral de Gipuzkoa sobre la atención a las personas mayores dependientes en la Comunidad Autónoma Vasca, la Comunidad Foral Navarra e Ipar Euskal Herria. El informe se enmarca en un proyecto más amplio de Eusko Ikaskuntza que tiene como objetivo crear un laboratorio de análisis y de innovación social en relación con el modelo de bienestar y a las políticas públicas que se desarrollan en el ámbito de los Servicios Sociales en los diferentes territorios de Euskal Herria: CAV, Navarra e Ipar Euskal Herria.

Aunque este laboratorio tiene como objetivo analizar el conjunto de las políticas que tienen que ver con el bienestar social - políticas de garantía de ingresos, de empleo, de apoyo a las familias, de inclusión social, de prevención y abordaje de la exclusión residencial, etc.- el primero de los informes realizados en el marco de este programa se refiere al envejecimiento y la atención a la dependencia, dada la importancia de los cuidados a las personas mayores y dependientes en el marco de los servicios sociales y su relevancia en lo que se refiere a la calidad de vida y a la cohesión social de toda la población.

En efecto, no cabe duda de que el ámbito de los cuidados ha tomado un papel protagonista en la agenda pública pues, sin cuidados sociales y sanitarios, difícilmente podemos ser una sociedad que resista a las crisis emergentes. El modelo de atención a los cuidados en nuestro territorio ha sido, y es, espacio de debate. Y no solo es debido a un crecimiento de la presión de los actores o la demanda por una cuestión meramente demográfica. Han surgido también cambios y nuevas necesidades derivadas de procesos de envejecimiento, donde las personas reclaman un mayor protagonismo en relación a cómo quieren ser cuidadas, evidenciando los límites del actual sistema.

El modelo de Atención Centrada en la Persona es un horizonte reclamado por proveedores y beneficiarios de recursos. Su implementación se exige tanto en los espacios de atención residencial como de cuidado domiciliario, y avanza hacia un modelo más adecuado a la diversidad de necesidades, con un mayor respeto a los derechos y voluntades de las personas mayores. La crisis de la covid-19 ha puesto de manifiesto la importancia del modelo de cuidados en la garantía de la supervivencia, un modelo con las debilidades de un sistema precarizado, con escasos medios humanos y materiales, y con un tejido profesional de gran valor técnico y humano. Desde este momento, cualquier debate sobre el modelo social y de bienestar de nuestras sociedades no podrá obviar la necesidad de poner en el centro de la discusión el modelo de cuidados que nuestra sociedad necesita. Ese debate sobre el modelo de cuidados puede sin duda enriquecerse a partir del análisis comparado de los modelos de servicios sociales que existen en Euskadi, en Navarra y en Ipar Euskal Herria, y del aprendizaje mutuo que se puede derivar de esas comparaciones.

A partir de esa reflexión, el trabajo realizado describe y compara el sistema de servicios sociales que existe en los tres ámbitos administrativos que conforman Euskal Herria para dar respuesta a las necesidades de las personas mayores dependientes. En ese sentido, el objetivo del trabajo es triple:

- Por una parte, describir el funcionamiento básico del sistema de servicios sociales para personas mayores o dependientes en cada territorio, de forma que puede ser conocido por las personas que no lo conocen en detalle.

- Por otra, ofrecer datos e indicadores que permitan dimensionar y poner en relación el alcance de esas políticas en cada territorio, desde el punto de vista del número de personas atendidas, los servicios ofrecidos, el personal ocupado o el gasto realizado.

- Por último, identificar las principales similitudes y divergencias que existen entre los tres territorios, identificar los retos comunes, así como los específicos de cada territorio, y plantear algunas recomendaciones para la mejora de los servicios en los tres territorios analizados, a partir de los aprendizajes extraídos.

\section{Metodología y estructura}

Desde el punto de vista metodológico, el informe realizado no se basa en una investigación específica, sino que pretende recoger la información y los datos disponibles a partir de muy diversas fuentes estadísticas y administrativas.

Esa necesidad de comparar datos de fuentes muy variadas ha planteado algunas dificultades de cara a la realización de este trabajo, ya que no siempre los indicadores disponibles para cada territorio son los mismos o se calculan de la misma forma. La propia definición del perímetro de las políticas analizadas y de las personas destinatarias es diferente en cada territorio, lo que dificulta la comparación entre las tres realidades administrativas que conforman Euskal Herria. En ese sentido, una de las primeras 
conclusiones del trabajo hace referencia a la dificultad para disponer de datos suficientemente homogéneos y comparables sobre el alcance de los servicios sociales en la CAV, Navarra e Ipar Euskal Herria e incluso a la dificultad para determinar cuáles son las políticas, los servicios y las prestaciones que deben tenerse en cuenta en cada uno de los territorios para un análisis homogéneo de modelo de cuidados y apoyos que existe en ellos.

Para poder dar respuesta a estas dificultades, las opciones metodológicas que se han tomado son las siguientes:

- La mayor parte de la información relacionada con Ipar Euskal Herria hace referencia, en realidad, al conjunto del departamento de Pirineos Atlánticos, ya que la información básica sobre el sistema de servicios sociales se ofrece en el Estado francés - en general- a nivel de departamento. La competencia del Consejo del Departamento en materia de acción social y la desagregación de los datos que se realiza habitualmente en el Estado francés en el ámbito estadístico hacen prácticamente imposible disponer de datos relativos únicamente a los territorios de Lapurdi, Behe Nafarroa y Zuberoa.

- En el caso de la CAV, pese a las notables diferencias que existen en cuanto al despliegue y el funcionamiento de los servicios sociales en cada uno de los tres territorios históricos, se ha optado en la mayor parte de los casos por ofrecer los datos para el conjunto de la comunidad, y solo en algunos casos los datos se han desagregado por territorio histórico.

- Los datos analizados y los servicios descritos se refieren fundamentalmente a las personas mayores en situación de dependencia. En algunos casos, sin embargo, la información disponible hace referencia al conjunto de las personas con dependencia, lo que incluye a menores y a personas adultas con discapacidad. No obstante, el informe no se centra en las políticas de atención a la discapacidad, que requerirían, en todo caso, un informe especifico.

- Del mismo modo, algunos de los datos que se ofrecen hacen referencia al conjunto de los servicios sociales, y no solo a los servicios sociales de atención a las personas con dependencia, puesto que, en ocasiones, la información relativa a los servicios sociales no diferencia la edad o la problemática de las personas atendidas.

- En algunos casos existen fuentes diversas para la obtención de los mismos o similares datos. En tales casos, especialmente a la hora de realizar comparaciones entre los territorios, se ha dado prioridad a las fuentes comunes o de ámbito superior, es decir, a las fuentes que ofrecen datos para al menos dos de los ámbitos territoriales analizados. Aunque en ocasiones esos datos no coincidan con los datos de las instituciones locales, se ha pensado que estas fuentes resultan más fiables a la hora de realizar comparaciones, ya que se basan en una metodología común y armonizada.

- Los datos no siempre hacen referencia a los mismos años. Se ha intentado en cualquier caso utilizar para cada tabla o gráfico los datos más recientes disponibles, que en general se refieren a los años 2017, 2018 y 2019, en función de la disponibilidad de datos de cada una de las fuentes utilizadas.

- Este es uno de los pocos estudios, que sepamos, en los que se analizan en detalle y se comparan los datos relativos a la oferta, la dotación de personal o el gasto de servicios sociales que se realiza en la CAV, Navarra y los Pirineos Atlánticos. El interés del trabajo no radica en cualquier caso en los datos tomados de forma aislada, sino en identificar las similitudes y las diferencias que existen en cada territorio y en extraer conclusiones globales que contribuyan al aprendizaje común.

Como se señalado previamente, este artículo resume un informe realizado por Eusko Ikaskuntza. A partir de los contenidos de ese informe, la estructura del artículo es la siguiente:

- El tercer apartado recoge una descripción básica de la articulación del sistema de atención a la dependencia en cada uno de los tres territorios analizados.

- El cuarto apartado algunos datos muy básicos sobre la estructura demográfica, las necesidades sociales y la demanda de servicios en la CAV, Navarra e Ipar Euskal Herria.

- De forma transversal, el siguiente apartado recoge las diferencias y similitudes que existen entre los tres modelos analizados.

- El apartado final recoge los retos, límites y potencialidades de cada modelo, diferenciando los que corresponden a las políticas estatales y los que corresponden a las medidas adoptadas en cada uno de los tres territorios estudiados.

\section{La atención a la dependencia en los territorios de Euskal Herria: elementos básicos}

\subsection{La atención a la dependencia en Ipar Euskal Herria}

En el caso de Ipar Euskal Herria y del departamento de Pirineos Atlánticos, el sistema de atención a la dependencia se articula fundamentalmente en torno a una prestación económica -la Allocation Personalisé d'Autonomie (APA)- que se concede a las personas mayores de sesenta años que acreditan una situación de dependencia mediante un baremo de ámbito estatal y con las que se establece un plan individualizado de atención. Se trata de 
una prestación universal, aunque su cuantía se modula en función del nivel de renta y del grado de dependencia, y con ella se financia tanto el acceso a los servicios de apoyo en el domicilio como el acceso a los centros residenciales.

Desde el punto de vista competencial, si bien el Estado central regula las características básicas del sistema, las principales competencias en cuanto a la financiación y la prestación de los servicios de atención a la dependencia recaen en los Consejos Generales de los departamentos, que asumen el liderazgo del sistema a nivel del territorio. La administración regional juega también un papel importante en lo que se refiere a la financiación y la articulación de los servicios de salud, así como en relación a los servicios sociales y sociosanitarios. Por su parte, los ayuntamientos desempeñan un papel secundario, si bien pueden desarrollar diversos servicios y prestaciones de forma discrecional, y pueden también ser titulares de servicios y centros de atención directa, como las residencias medicalizadas para personas mayores (EHPAD) o los servicios de acompañamiento y atención a domicilio (SAAD). En ese contexto, juega un papel de creciente importancia en Ipar Euskal Herria la Mancomunidad de Municipios de la Aglomeración del País Vasco, que presta de forma mancomunada diferentes servicios a escala local.

Desde el punto de vista de la provisión de los servicios, y en aplicación del principio de libre elección, las personas usuarias pueden acceder -mediante la APA - a los servicios y centros de su elección, que pueden estar gestionados bien por entidades públicas (dependientes de ayuntamientos o de hospitales), o bien por entidades privadas con o sin fin de lucro.

Como se explica en las páginas siguientes, el sistema francés de atención a la dependencia destaca también por la estrecha coordinación entre el ámbito social, el sanitario y el sociosanitario, por la existencia de un sistema de triple tarificación para la determinación de la participación económica de las personas usuarias en la financiación de las residencias y por la existencia de un sistema de cotización sobre los salarios que abonan las empresas y mediante la cual se cofinancian los gastos de atención a la dependencia. Con relación a Euskadi y Navarra, el sistema de atención a la dependencia se caracteriza en Ipar Euskal Herria por el escaso impulso que desde la Administración se da al trabajo en red de los diversos agentes, y el menor protagonismo de las dinámicas de participación y coordinación entre los agentes públicos y la sociedad civil.

\subsection{La atención a la dependencia en la Comunidad Foral de Navarra}

En el caso de la Comunidad Foral Navarra, el sistema de atención a la dependencia se enmarca tanto en el Sistema de Autonomía y Atención a la Dependencia (SAAD), de ámbito estatal, como en el sistema navarro de servicios sociales, de ámbito autonómico (foral). Si bien la regulación general, y una parte de la financiación, se establecen a nivel estatal, los servicios se prestan en el marco de los servicios sociales, regulados por la Ley de Servicios Sociales de Navarra de 2006. En ese marco, la mayor parte de los servicios son prestados por la Agencia Navarra de Autonomía y Atención a la Dependencia, dependiente del Gobierno de Navarra, si bien los ayuntamientos están también obligados a prestar desde los servicios sociales de base un programa de promoción de la autonomía y atención a la dependencia que incluye el Servicio de Asistencia Domiciliaria (SAD).

En aplicación tanto de la Ley de Dependencia estatal como de la Ley de Servicios Sociales de Navarra, la mayor parte de los servicios de atención a las personas con dependencia tienen carácter garantizado, es decir, deben ser ofrecidos a las personas que cumplen los requisitos de acceso, y no tienen por tanto carácter discrecional.

En lo que se refiere a la oferta de servicios, la cartera se divide en prestaciones económicas y servicios de atención directa; al igual que en la CAV, la principal prestación contemplada por el sistema es la Prestación Económica de Cuidados en el Entorno Familiar (PECEF), a la que acceden casi la mitad de las personas usuarias de servicios de atención a la dependencia. Le siguen en orden de importancia los servicios residenciales y el servicio de teleasistencia.

En cuanto a la provisión de los servicios, pueden ser o bien directamente prestados por las Administraciones Públicas o bien prestados -mediante contrato, convenio o concierto-por entidades privadas con o sin fin de lucro. También existe un número relativamente importante de plazas privadas, sin financiación pública alguna, a las que acceden las personas que no están en una situación de dependencia o que están en lista de espera para acceder a una plaza de responsabilidad pública.

\subsection{La atención a la dependencia en la Comunidad Autónoma Vasca}

El modelo de la CAV coincide en buena medida con el existente en la Comunidad Foral Navarra, debido en parte a que en ambos territorios se aplica la Ley de Dependencia estatal. En ese sentido, el catálogo de servicios y centros es similar, y también en la CAV tiene un papel protagonista la Prestación Económica de Cuidados en el Entorno Familiar (PECEF), que compensa los cuidados prestados por las personas cuidadoras informales. Le siguen en importancia, también como en Navarra, los centros residenciales y la teleasistencia. Tanto la Ley de Dependencia como la Ley vasca de Servicios Sociales de 2008 garantizan el derecho subjetivo a los servicios de atención a todas las personas que acrediten cumplir los requisitos de acceso, independientemente de su renta, de acuerdo al principio de universalidad que ambas leyes consagran. Para ello, la Ley de Servicios Sociales vasca establece un amplio catálogo de 
servicios, centros y prestaciones, que deben obligatoriamente ser ofertados a las personas que cumplen los requisitos de acceso.

Como en el conjunto del Estado, y como también ocurre en Navarra, los proveedores de los servicios sociales de atención a la dependencia pueden ser en la CAV tanto entidades públicas como entidades privadas, con o sin fin de lucro. En ese sentido, la Ley de Servicios Sociales vasca prevé la posibilidad de que la gestión de los centros pueda encomendarse a entidades de cualquier titularidad, si bien establece que, a los efectos de establecimiento de conciertos, las Administraciones Públicas darán prioridad, cuando existan análogas condiciones de eficacia, calidad y costes, a las entidades dedicadas a la prestación de servicios sociales que tengan carácter no lucrativo. A diferencia de lo señalado para Ipar Euskal Herria, y como ocurre en Navarra, no puede decirse que la libertad de elección sea un principio relevante a la hora de diseñar el acceso de las personas dependientes a los servicios que les corresponden. En ese sentido, es la propia Administración la que concierta o contrata los servicios a los proveedores externos, o la que los presta de forma directa, y sólo en casos muy concretos se plantea el acceso directo de los usuarios a los servicios y centros de su elección a través de una prestación económica, como ocurre en el Estado francés.

La estructura competencial de los servicios sociales vascos se caracteriza por su alto grado de descentralización: como en Navarra, los servicios se diferencian en dos niveles de atención - primaria y secundaria-, correspondiendo la gestión y la financiación de los servicios sociales de atención primaria a los municipios -independientemente de su tamaño- y la gestión de los servicios sociales de atención secundaria, así como la mayor parte de las prestaciones económicas a las diputaciones forales de Álava, Gipuzkoa y Bizkaia. El Gobierno Vasco asume las funciones de regulación y planificación, así como la prestación de algunos servicios de atención directa (fundamentalmente, el servicio de teleasistencia).

\section{Estructura demográfica, necesidades sociales y demanda de servicios}

La población que reside en los tres territorios analizados en este informe asciende a 3,5 millones de personas, de las que el $62 \%$ reside en la CAV, el $18 \%$ en la Comunidad Foral de Navarra y el $19 \%$ en el Departamento de Pirineos Atlánticos. La densidad de población es muy superior en la CAV con respecto a los otros dos territorios, así como el tamaño medio de los municipios: los municipios de la CAV tienen un tamaño medio de 8.764 habitantes, frente a $\mathbf{2 . 4 0 5}$ en Navarra y 1.240 en Pirineos Atlánticos, donde el número de ayuntamientos supera el medio millar.

En lo que se refiere al PIB por habitante, con datos para 2016 en el caso de Pirineos Atlánticos, 2017 en el caso de Navarra y 2018 en el caso de la CAV, de acuerdo a Eurostat, oscila entre 27.300 euros en el Departamento de Pirineos Atlánticos y 36.300 euros en el caso de la CAV.

Tabla 1. Indicadores geográficos comparados

\begin{tabular}{l|c|c|c}
\cline { 2 - 4 } & $\begin{array}{c}\text { Comunidad } \\
\text { Autónoma } \\
\text { Vasca }\end{array}$ & Navarra & $\begin{array}{c}\text { Pirineos } \\
\text { Atlánticos }\end{array}$ \\
\hline Población total & 2.199 .711 & 654.214 & 677.309 \\
\hline № de municipios & 251 & 272 & 546 \\
\hline $\begin{array}{l}\text { Tamaño medio de } \\
\text { los municipios }\end{array}$ & 8.764 & 2.405 & 1.240 \\
\hline $\begin{array}{l}\text { Densidad de } \\
\text { población* }\end{array}$ & 303 & 63 & 84 \\
\hline $\begin{array}{l}\text { PIB per cápita (en } \\
\text { PPA)** }\end{array}$ & 36.300 & 33.700 & 27.300 \\
\hline
\end{tabular}

* Habitantes por kilómetro cuadrado.

** PPA: paridad de poder adquisitivo.

Fuente: Elaboración propia a partir de NASTAT, EUSTAT, INSEE y Eurostat.

Aunque el porcentaje que representan las personas mayores de sesenta y cinco años con relación al

Tabla 2. Indicadores sociodemográficos comparados

\begin{tabular}{|c|c|c|c|}
\hline & Comunidad Autónoma Vasca & Navarra & Pirineos Atlánticos* \\
\hline Tamaño medio de los hogares & 2,4 & 2,5 & 2,1 \\
\hline Tasa de fecundidad & 35,1 & 37,9 & 43,4 \\
\hline Índice de envejecimiento de la población & 154,0 & 121,5 & 120,5 \\
\hline$\%$ mayores de 65 & 22,6 & 19,8 & 24,2 \\
\hline$\%$ mayores de 75 & 11,3 & 9,9 & 11,9 \\
\hline$\%$ mujeres entre mayores de 75 & 61,6 & 59,9 & 61,4 \\
\hline$\%$ mayores de 65 que viven solos & 22,7 & 25,4 & 33,9 \\
\hline Esperanza de vida a los 65 años (hombres)** & 19 & 20 & 24 \\
\hline Esperanza de vida mujeres a los 65 años (mujeres)** & 23 & 24 & 28 \\
\hline \% pensiones de jubilación inferiores a 600 euros & 15,4 & 14,7 & 10,1 \\
\hline
\end{tabular}

* Los datos se refieren a 2017.

** En el caso de Pirineos Atlánticos se recoge la esperanza de vida a los 60.

Fuente: Elaboración propia a partir de EUSTAT, INE, INSEYE, SAAD y Observatorio de la Realidad Social del Gobierno de Navarra. 
conjunto de la población es similar en los tres territorios (oscila entre el 19,8\% de Navarra y el 24,2\% de Pirineos Atlánticos), el peso de la población mayor de 65 años con relación a la población menor de dieciséis -es decir, el índice de envejecimiento- es muy superior en la CAV, debido a sus reducidas tasas de natalidad y al escaso peso de la población menor de edad en su estructura poblacional. El peso de la población mayor de setenta y cinco años oscila entre el 9,9\% de Navarra y el $11,9 \%$ de la CAV, en la línea del $9,7 \%$ que se registra en la UE-27. En torno al $60 \%$ de las personas mayores, en los tres territorios, son mujeres. El porcentaje de mayores de sesenta y cinco años que viven solos es mayor en Pirineos Atlánticos $-33,9 \%$ - que en los dos territorios peninsulares. La esperanza de vida a los sesenta y cinco años ronda en los tres territorios los 20 años.

\section{La atención a la dependencia en los territorios de Euskal Herria: principales diferencias y similitudes}

El análisis realizado en el informe del que se deriva este artículo permite identificar diferencias y similitudes importantes entre los tres territorios de Euskal Herria en relación al sistema de atención a las personas mayores dependientes.

Entre las principales similitudes, cabe destacar las siguientes:

- Más allá de su carácter sociosanitario, el sistema de atención a la dependencia y/o de servicios sociales tiene en los tres territorios un contorno peor definido, un perímetro más borroso, que en el caso de otros sistemas de bienestar, como el de la salud o el de la educación. La confusión entre los servicios sociales, los servicios sociosanitarios y los de atención a la dependencia, la constante invocación a un cuarto -o quinto- riesgo o pilar del Estado de Bienestar y la dificultad para delimitar adecuadamente tanto las necesidades cubiertas como los servicios y prestaciones incluidas, así como las personas atendidas y los mecanismos de financiación, ilustran en qué medida el grado de madurez de estos servicios es muy inferior al de los sistemas de bienestar clásicos (educación, sanidad, etc.). La situación es a este respecto similar en los tres territorios analizados.

- La crisis de los cuidados -es decir, la dificultad para dar una respuesta a los cuidados que precisa una población mayor cada vez más longeva y abundante, en un marco determinado por la reducción de la capacidad de apoyo de las redes informales debido, entre otros factores, a la incorporación de las mujeres al mercado de trabajo- afecta de la misma forma a los tres territorios. El número de personas mayores con necesidades de atención es cada vez mayor tanto en la CAV como en Navarra e Ipar Euskal Herria - que se cuentan entre las regiones más envejecidas de Europa-, mientras se reducen las posibilidades de las redes informales para dar una atención adecuada a las personas mayores dependientes, y crece la demanda sobre los servicios profesionales, ya sean públicos o privados.

- En ese marco, y al menos en el aspecto teórico, las instituciones de los tres territorios apuestan por el domicilio y por el entorno comunitario -frente a la institucionalización en grandes centroscomo forma prioritaria de atención a las personas dependientes. El mantenimiento de las personas mayores en su domicilio (ageing in place) orienta el diseño de las políticas sociales y sociosanitarias de atención a la dependencia tanto en la CAV como en Navarra y en Ipar Euskal Herria.

- También en los tres territorios puede hablarse de una tendencia hacia el refuerzo de las redes y las iniciativas de autoorganización comunitaria, que permitan combinar los servicios formales de responsabilidad pública con recursos vecinales, asociativos y de proximidad.

- En una línea similar, puede decirse que se observa en los tres territorios una cierta tendencia al desarrollo de fórmulas de alojamiento alternativo - residences autonomie- en Ipar Euskal Herria, viviendas comunitarias y apartamentos tutelados en Navarra y la CAV- que ocupan un espacio intermedio entre el domicilio y los centros residenciales convencionales, así como al desarrollo de unidades residenciales de menor tamaño y de ambiente más hogareño.

- También existen grandes similitudes en los tres territorios en lo que se refiere al diseño de un modelo mixto en cuanto a la provisión de servicios, en un marco de responsabilidad pública. En ese sentido, los tres territorios cuentan con un sistema garantizado y universal de acceso a los servicios, cuya provisión se encomienda -mediante diversas fórmulastanto a entidades de titularidad pública como a entidades de titularidad privada con o sin fin de lucro. Aunque algunos sectores, al menos en algunos de los territorios analizados, han criticado lo que consideran una privatización de los servicios y han apostado por su publificación, el modelo mixto de provisión de servicios de responsabilidad pública no parece estar en cuestión en ninguno de los territorios analizados.

- En los tres territorios puede hablarse además de un derecho subjetivo y universal ante el riesgo de dependencia, de forma que todas las personas que acreditan un nivel determinado de necesidad tienen un derecho garantizado a recibir unos servicios o prestaciones determinadas. En los tres territorios, además, ese derecho se desvincula de la situación económica, si bien el nivel de renta, así como el grado de dependencia, sí se tiene en cuenta a la hora de determinar la participación económica de las personas usuarias en la financiación de los servicios y/o en el montante de las ayudas percibidas. 
- Aunque el modelo de financiación de los servicios sociales es muy diferente en los tres territorios, los principales servicios están sujetos a copago tanto en la CAV, como en Navarra y en Ipar Euskal Herria. El diseño del copago es, sin embargo, diferente: el sistema francés resulta teóricamente más transparente y racional, aunque impone al mismo tiempo mayores cargas económicas a las personas usuarias, debido, en cualquier caso, al mayor coste de las plazas residenciales, ya que el porcentaje de copago respecto al coste total es similar en los tres territorios. El Estado francés cuenta además con una serie de beneficios fiscales que reducen en la práctica el importe del copago.

- Aunque la cuestión de las condiciones laborales no ha podido ser analizada en detalle en este trabajo -debido, entre otras razones, a la dificultad para disponer de datos comparables-, puede decirse que en los tres territorios existen problemas importantes en lo que se refiere al reclutamiento, la cualificación, la dotación y las condiciones laborales del personal, que se traducen, entre otras consecuencias, en una conflictividad laboral elevada. Estas carencias en lo que se refiere a la formación, la dotación y las condiciones de trabajo de las personas profesionales tienen, además, una incidencia importante en la calidad de la atención y en la calidad de vida de las personas atendidas.

- En los tres territorios cabe hablar, por otra parte, de un sistema de atención muy determinado por los roles sociales de género, en la medida en que la mayor parte de las personas atendidas, de las personas cuidadoras y de las personas profesionales son mujeres.

- También cabe hablar, aunque esta cuestión apenas se ha analizado en el informe, del incremento en la edad media de las personas atendidas y de la concentración en los centros residenciales de personas con niveles de dependencia cada vez más severos.

- Finalmente, cabe destacar que los datos obtenidos en este trabajo permiten hablar de una cierta similitud en lo que se refiere a la proporción de personas atendidas en los tres territorios, con tasas de cobertura equiparables en la CAV, Navarra y el Departamento de Pirineos Atlánticos en lo que se refiere a los servicios de atención directa.

En sentido contrario, las principales diferencias identificadas ${ }^{1}$ son las siguientes:

- Una de las principales diferencias se refiere al papel de las prestaciones económicas y, en ese sentido, a la idea de libertad de elección de los servicios y centros a los que las personas acuden.

${ }^{1}$ Aunque la mayor parte de las diferencias se dan entre el Estado francés y el español, también cabe hablar de diferencias importantes entre la CAV y la Comunidad Foral Navarra y, dentro de estas, entre los diferentes territorios, comarcas o municipios.
En ese sentido, siguiendo la tónica general en otros países de Europa -el caso alemán es al respecto paradigmático ${ }^{2}-$ el modelo establecido en el Estado francés se basa en la concesión de una prestación económica mediante la cual las personas usuarias financian una parte del coste de los servicios que reciben. Teóricamente al menos, las personas perceptoras de la prestación pueden acceder a centros o servicios de diversa titularidad - pública, privada mercantil o privada sin fin de lucro- en función de su preferencia y siempre, lógicamente, que exista una oferta suficiente de servicios en su territorio. En ese marco, los servicios de titularidad pública compiten con los de titularidad privada en un marco determinado por la oferta y la demanda. El modelo existente al sur de la muga es diferente: aunque se han ido extendiendo este tipo de prestaciones, es en general la Administración la que contrata o concierta los servicios, y la capacidad de elección de las personas usuarias se ve restringida por la relativa rigidez de los sistemas de acceso a los servicios.

- Otra de las diferencias relevantes entre los territorios pertenecientes al Estado español e Ipar Euskal Herria se refiere a la composición y la amplitud de la cartera de servicios disponibles. En ese sentido, tanto Navarra como la CAV disponen de catálogos y carteras muy amplias, con servicios y prestaciones de muy diverso tipo. En el Estado francés, la oferta es por el contrario menos exuberante, más limitada y en cierto sentido más genérica. Las personas acceden a un número determinado de servicios o prestaciones mediante la APA, pero la definición legal del catálogo de servicios es, por decirlo de alguna forma, más abierta que en las carteras de servicios de la CAV y de Navarra. En estos territorios, sin embargo, la detallada definición que en los textos legales se hace de los servicios teóricamente disponibles no garantiza su despliegue efectivo ni su disponibilidad especialmente en lo que se refiere a los servicios de atención primaria- para el conjunto de las personas que pudieran requerirlos.

- En ese marco, el estudio realizado ha puesto de manifiesto que las coberturas de atención directa son relativamente similares en los tres territorios, y que en ambos la extensión de los centros

2 Una de las principales características del modelo alemán de atención a la dependencia se refiere al papel que en el marco de este sistema se da a la competencia entre diferentes proveedores y a la capacidad de elección de las personas usuarias. En ese marco, las barreras de acceso de los operadores al mercado son mínimas y la apertura de centros o servicios de atención se permite siempre que se cumpla una serie de requisitos mínimos (estructurales, ratios y cualificaciones de personal, etc.). La capacidad de elección de los consumidores se pretende facilitar o garantizar mediante el impulso a la transparencia, lo que implica el énfasis en la realización obligatoria, con carácter anual, de visitas de inspección y la publicación de sus resultados en Internet. La lógica que subyace al sistema es la de que los centros estarán interesados en garantizar una buena calidad de la atención, en la medida en que ello se reflejará en sus calificaciones $y$, a su vez, en una mayor demanda por parte de posibles usuarios (Leturia, Zalakain, Mendieta y Carcavilla, 2019). 
residenciales y de los servicios de asistencia domiciliaria son parecidos (si bien, cabe pensar, la intensidad de la asistencia domiciliaria es mayor en el Departamento de Pirineos Atlánticos). La principal diferencia se debe en cualquier caso al papel que en los territorios peninsulares juegan la teleasistencia y, sobre todo, la Prestación Económica de Cuidados en el Entorno Familiar (PECEF). Aunque su extensión no es la misma en los cuatro territorios peninsulares, la PECEF, ausente en Ipar Euskal Herria, es la principal respuesta que el sistema de servicios sociales ofrece a las personas mayores en Navarra y en la CAV. La opción -tanto política como social- por una prestación destinada a compensar el cuidado informal frente a los servicios de atención directa profesional, tiene implicaciones decisivas en la configuración del sistema de atención a la dependencia en el conjunto del Estado español y también, lógicamente, en Navarra y en la CAV.

- La distribución competencial y la arquitectura institucional del sistema es muy diferente en los tres territorios analizados.

- En Ipar Euskal Herria, el protagonismo corresponde claramente al Consejo Departamental, que ejerce el liderazgo en relación a la acción social, si bien el Estado y los ayuntamientos mantienen algunas competencias y funciones.

- En Navarra, aunque los servicios sociales de atención primaria $-y$, dentro de ellos, los servicios de asistencia domiciliariacorresponden a los ayuntamientos, es el Gobierno de Navarra el que tiene un mayor protagonismo, tanto desde el punto de vista de la regulación, la planificación y la financiación como desde el punto de vista de la prestación de los servicios sociales especializados.

- El modelo más descentralizado y, por tanto, complejo es el correspondiente a la CAV. El Gobierno autonómico tiene encomendadas las competencias de regulación y de planificación - así como las correspondientes a la alta inspección-, mientras que los servicios de atención secundaria son prestados por las diputaciones forales de Álava, Bizkaia y Gipuzkoa. Los ayuntamientos independientemente de su tamaño- son responsables de articular una cartera de servicios sociales de atención primaria mucho más amplia que la correspondiente a los ayuntamientos de Ipar Euskal Herria e incluso de Navarra. En ese marco, el riesgo de fragmentación es alto, las diferencias territoriales son importantes y la gobernanza del sistema -encomendada a un órgano interinstitucional paritario- compleja.

- En lo que se refiere a la coordinación entre los diversos agentes, como antes se ha señalado, en relación al menos con lo que ocurre en Euskadi y Navarra, el sistema de atención a la dependencia se caracteriza en Ipar Euskal Herria por el escaso impulso que desde la Administración se da al trabajo en red de los diversos agentes y el menor protagonismo de las dinámicas de participación y coordinación entre los agentes públicos y la sociedad civil.

- La respuesta que se da a las necesidades sanitarias de las personas usuarias de los centros residenciales es también muy diferente. En ese sentido, el carácter medicalizado de los EHPAD contrasta con un modelo de atención sanitaria en las residencias escasamente articulado en la CAV y en Navarra.

- Una de las principales diferencias identificadas en el estudio se refiere a la dotación del personal que existe en los servicios sociales del Departamento de Pirineos Atlánticos en relación con la dotación profesional en la CAV y en Navarra. Si bien las diferencias entre la CAV y Navarra son relativamente pequeñas -el empleo en el ámbito de los servicios sociales en la CAV representa el 3,9\% de la afiliación y en Navarra el 3,3\%-, las diferencias entre Ipar Euskal Herria y los territorios pertenecientes al Estado francés son muy notables, ya que las personas ocupadas en este sector representan el 9,2\% de todas las personas ocupadas, con 37 trabajadores/as por cada mil habitantes, frente a 17 en la CAV y 14 en Navarra. Las razones de estas diferencias no están claras y pueden deberse a una mayor dotación en otros ámbitos de la acción social en Ipar Euskal Herria, a unas ratios o intensidades de atención más elevadas o al papel que juegan, en Navarra y en la CAV, las personas que trabajan en el servicio doméstico a la hora de la provisión de cuidados a las personas dependientes.

- Existen, finalmente, diferencias muy significativas en cuanto a la financiación de los servicios, especialmente entre los territorios de Ipar Euskal Herria y los que pertenecen al Estado español. Las diferencias son tres:

- En el Estado francés, a diferencia de lo que ocurre en la CAV y en Navarra, la administración sanitaria financia de forma estructural una parte importante de los servicios residenciales.

- El sistema de copago se articula en función de un sistema de triple tarificación; el coste relativo al funcionamiento de los centros se divide en tres categorías diferentes, con fuentes de financiación y formas de determinación de las tarifas también diferentes: la tarifa de dependencia cubre el coste de la atención a las necesidades derivadas de las situaciones de dependencia y de los apoyos necesarios para la realización de las actividades de la vida diaria y se abona fundamentalmente a través de la APA; la tarifa de alojamiento cubre los costes hoteleros y de manutención, así como otros costes relacionados con la limpieza y la lavandería, las actividades recreativas y de animación, la administración general del centro, etc. Esta 
tarifa es íntegramente abonada por la persona usuaria, salvo que carezca de recursos económicos suficientes, en cuyo caso se accede a las prestaciones de asistencia social correspondiente; la tarifa sanitaria cubre los costes derivados de la atención sanitaria y es financiada por el seguro de salud.

- Una parte de los servicios de atención a la dependencia son financiados mediante una cotización específica que abonan las empresas. Esta cotización equivale al 0,3\% de la masa salarial y para su introducción se eliminó un día festivo en el calendario laboral ${ }^{3}$.

\section{Retos y limitaciones}

\subsection{Retos y limitaciones de los modelos estatales}

\section{a. El caso español}

Tras casi 15 años de Ley de Dependencia, la atención a los cuidados en España mantiene un sistema de gestión y provisión fragmentado entre Administraciones, con modelos de atención desconectados entre los servicios de atención en el entorno como el SAD o la atención residencial, con fuertes limitaciones para dotar de intensidad de cuidados suficientes a personas que por sus bajos ingresos no pueden optar a la complementariedad de recursos privados y el mantenimiento de un modelo de atención más asistencial que inclusivo con el entorno y las necesidades de la persona. La ley implicó la promoción de un modelo de cuidados de larga duración en España que apostó por avanzar hacia un sistema universal, sin revisar el modelo de gestión fragmentado y descentralizado existente, que se vio más acuciado por la falta de criterios claros en torno a las responsabilidades entre los distintos niveles de gestión (Aguilar-Hendrickson, 2020).

A estas inconsistencias en la definición del modelo se suman limitaciones en términos de inversión. España se encuentra lejos de los países del entorno, su inversión se sitúa por debajo de la media europea, y el modelo se ha caracterizado históricamente por priorizar la atención residencial de carácter privado y mercantil, a pesar de que la preferencia de la población mayor es la de residir en sus propios hogares y recibir atención a domicilio (Díaz Veiga y Sancho, 2013), y del potencial preventivo de estos cuidados contra la aparición de situaciones de dependencia.

Es por ello que el desarrollo del Sistema para la Autonomía y la Atención a la Dependencia (SAAD) a partir de 2006 ha ido consolidando

${ }^{3}$ En la CAV y en Navarra, por el contrario, los servicios de atención a la dependencia se financian mediante impuestos ordinarios, sin que -registrando ambos territorios niveles de presión fiscal comparativamente bajos- se haya planteado la necesidad de diseñar fuentes de financiación finalistas que contribuyan a la sostenibilidad de los servicios sociales. un modelo de protección que mantiene, al menos en ciertas comunidades autónomas, características asistenciales. En ese contexto, los servicios de atención directa están en la práctica preferentemente orientados a personas dependientes con bajos ingresos, mientras que la población con ingresos medios y altos sigue recurriendo, en mayor medida, a la provisión privada. Esto último, fundamentalmente, por dos cuestiones: la preeminencia de las prestaciones económicas frente a servicios personales que ha caracterizado al sistema no ha hecho sino reforzar el papel de las familias en la atención de las personas dependientes -especialmente entre los hogares con menos ingresos-, dificultando los procesos de inclusión laboral femeninos; además, ha sido habitual la adquisición de cuidados en el mercado informal, generando un espacio socioeconómico - principalmente ocupado por población femenina extranjera- fuertemente caracterizado por la exclusión y la precariedad. Aunque la situación en las diferentes comunidades autónomas es muy distinta, la definición del copago - muy condicionada por la renta- también se relaciona con esta tendencia a la focalización en las personas con rentas más bajas y/o necesidades de atención muy intensas.

Con estas limitaciones propias del modelo de provisión de cuidados actual, se identifican algunos obstáculos que reducen su capacidad de atención. Distintos análisis que revisan el modelo de provisión público, residencial u otras necesidades vinculadas con la soledad, por ejemplo, coinciden en proponer un modelo de gestión más ágil que derive hacia un enfoque más conectado con el entorno o la comunidad, que promueva una acción preventiva más integrar y que intervenga desde el modelo de atención centrado en la persona (Martínez, DíazVeiga, Sancho y Rodríguez, 2014; Zalakain, 2017; Martínez-Virto y Hermoso, 2020).

En un sentido más específico, trabajos anteriores (SIIS, 2020) han puesto de manifiesto las siguientes limitaciones en el caso del sistema español de atención a la dependencia:

- Escaso desarrollo de los servicios de carácter preventivo y de apoyo en el domicilio, debido en parte con la debilidad de los servicios sociales de atención primaria, de competencia municipal. El Servicio de Asistencia Domiciliaria no responde, en líneas generales, a las necesidades de las personas con necesidades de apoyo moderadas 0 severas que residen en sus domicilios.

- Escasa cobertura e intensidad de los servicios públicos que reciben la mayor parte de las personas con dependencia y persistencia de bolsas importantes de personas con dependencia reconocida que no acceden a ningún servicio (lo que se conoce como "limbo de la dependencia”). El elevado número de personas que se encuentran en lista de espera para recibir las prestaciones siguen siendo un tema de especial preocupación, ya que suponían antes del coronavirus cerca 
del $20 \%$ de todas las personas con derecho a prestaciones.

- Debilidad de los servicios de apoyo a las personas cuidadoras.

- Diferencias interterritoriales muy acusadas en lo que se refiere a la calidad, la cobertura o la financiación de los servicios, lo que supone la existencia de modelos de atención claramente dispares. No cabe duda de que la compleja y en cierta medida disfuncional estructura competencial y territorial del sistema de servicios sociales ha contribuido a un desarrollo insuficiente y desigual de los cuidados de larga duración.

- Peso excesivo de las prestaciones económicas sobre los servicios de atención directa, si bien en los últimos años su peso se ha ido reduciendo y representan en la actualidad en torno al $40 \%$ de todas las prestaciones.

- El protagonismo de la prestación de cuidados en el entorno familiar ha reforzado la responsabilidad de las familias en la prestación de cuidados y, probablemente, el recurso a los cuidados privados a domicilio, a menudo prestados por mujeres inmigrantes contratadas de forma irregular. La cualificación de estas mujeres no siempre es suficiente y sus condiciones laborales son por lo general muy deficientes.

- Problemas de financiación: el gasto público global destinado a los servicios de larga duración es comparativamente bajo, la financiación del Gobierno central es más reducida de lo inicialmente previsto, y los niveles de copago son elevados, especialmente para las personas de rentas medias y altas. Ese menor gasto público se relaciona con el escaso nivel retributivo que obtienen en los trabajadores/ as del sector. De hecho, las malas condiciones laborales caracterizan un sector en el que las mujeres son ampliamente mayoritarias. Además, las ratios asistenciales varían claramente de unas comunidades a otras y son, en general, insuficientes.

- En un marco de restricciones al gasto público, una parte importante de los servicios públicos son prestados por entidades privadas, con o sin fin de lucro. De acuerdo a los datos del Imserso, solo el $60 \%$ de las plazas residenciales o de centro de día tienen financiación pública. En esos casos, además, la financiación pública es insuficiente, lo que se refleja en niveles de calidad insuficientes.

Los análisis realizados en relación al sistema de cuidados de larga duración en España -y, más concretamente, en relación al modelo de atención residencial- han puesto también de manifiesto la necesidad de reflexionar sobre el modelo de atención y sobre los recursos que se le destinan. Es necesario en ese sentido replantearse el diseño y la organización de las residencias y tender hacia fórmulas más pequeñas, más hogareñas, más personalizadas y mejor conectadas a la comunidad. Son necesarios más recursos -más profesionales, más formación, mejores salarios, etc.-, pero el mero incremento de los recursos tendrá escaso impacto si no se avanza paralelamente hacia nuevos modelos residenciales y de atención en la comunidad (Zalakain, 2020) ${ }^{4}$.

La epidemia de la covid-19 ha puesto finalmente de manifiesto, en el caso español, la necesidad de reflexionar sobre la medicalización de las residencias y sobre la coordinación entre los servicios sociales y los servicios de salud. Más allá del retraso en la aplicación de medidas de aislamiento, las dificultades para mantener las dotaciones de personal o las limitaciones en el acceso a pruebas diagnósticas y material de protección, una de las claves que explica el impacto de la covid-19 en las residencias se refiere a la atención sanitaria que sus usuarios reciben. La pandemia ha reavivado el debate sobre la muy desigual asistencia sanitaria que se presta en estos centros y sobre la necesidad de avanzar hacia una mayor integración sociosanitaria. Las residencias, en cualquier caso, no deben medicalizarse ni convertirse en hospitales de media estancia. Las residencias son - han de ser- lugares para vivir, el hogar de las personas que allí residen. $Y$ es responsabilidad de la administración sanitaria ofrecer a estas personas, como al conjunto de la población, la atención que precisan, en el momento y en el lugar en el que la precisan.

\section{b. El caso francés}

El envejecimiento de la población francesa y el aumento de las situaciones de dependencia física y psíquica constituyen un fenómeno complejo que todas las proyecciones demográficas confirman. La sociedad francesa, como la mayoría de las sociedades occidentales, se verá afectada de forma duradera por esta situación. Se trata de un desafío médico, social y financiero que sigue estando muy subestimado y que sólo una política cuidadosamente preparada y construida puede ayudar a afrontar. La crisis sanitaria provocada por el coronavirus y las numerosas muertes en residencias han reforzado la convicción de que es necesario mejorar la atención a las personas mayores dependientes. En Francia, esta cuestión se plantea tanto más cuanto que se estima hoy en día que el $25 \%$ de las personas de las generaciones del baby boom la tendrán que sufrir. En 2030, 21 millones de personas mayores de sesenta años vivirán en Francia, de las cuales tres millones perderán su autonomía, según las últimas proyecciones de la DREES y del INSEE (Larbi

\footnotetext{
${ }^{4}$ La falta de recursos es patente, especialmente en algunas comunidades. Sin embargo, la principal carencia de los centros residenciales no tiene tanto que ver con los recursos sino con la orientación general del modelo. Las residencias - muchas de ellas- siguen siendo una extraña mezcla de cuartel, hospital y hotel, pero pocas veces se plantean como lo que realmente debieran ser: el hogar de la gente que reside en ellas, un lugar para vivir como en casa. El problema no se limita pues a mejorar las condiciones de la plantilla y las ratios, ni a revertir la privatización. Es el propio modelo el que debe ser revisado completamente.
} 
y Roy, 2019), basadas en una definición amplia de la pérdida de autonomía.

En 2050, los mayores de sesenta años serán 25 millones, de los cuales cuatro millones perderán su autonomía; la población de sesenta años o más reside mayoritariamente en tres tipos de residencia: viviendas personales (población denominada "en hogares ordinarios"), hábitats intermedios, como residencias autónomas, y centros de acogida para personas mayores dependientes y asimiladas (residencias, unidades de cuidados de larga duración, establecimiento de alojamientos para personas mayores no EHPAD). La elección del lugar de residencia depende en gran medida del nivel de autonomía de la persona, pero también de las plazas disponibles en los establecimientos de acogida.

Los límites del modelo francés son de cinco órdenes: estructural, económico, estratégico formativo y operativo.

En el plano estructural, la falta de flexibilidad del sistema (en cuanto a la congruencia de sus mecanismos afectados por los límites de la descentralización) genera un déficit de transversalidad, de complementariedad en la perspectiva de acompañar la evolución de las situaciones (el paso del domicilio a la institución tropieza, por ejemplo, con la complejidad y la lentitud de los procedimientos).

En el plano financiero, el aumento del número de personas afectadas desborda los medios asignados, tanto desde el punto de vista de las disposiciones legales facilitadoras (con respecto a una consideración lo más cercana posible a las necesidades de las personas y de sus familias) como del número de profesionales asignados a su acompañamiento (algunos estudios señalan también el déficit de competencias relativas a determinadas problemáticas).

Desde el punto de vista estratégico, es difícil dar prioridad a un escenario director (capaz de dirigir las proyecciones para los próximos años). Se corre el riesgo de perpetuar un modelo que solo responde parcialmente a las necesidades emergentes. Las prácticas actuales de internamiento en instituciones de las personas de edad en situación de pérdida de autonomía supondrían duplicar el ritmo de apertura de plazas observado desde 2012, con el fin de acoger a 108.000 residentes suplementarios en residencias (establecimientos de alojamiento para personas mayores dependientes o EHPAD) entre 2019 y 2030 , y a 211.000 más entre 2030 y 2050 , que se añadirían a los 611.000 residentes en las plazas existentes.

Sin embargo, el hecho de favorecer la permanencia en el hogar y limitar las plazas en residencias, como promueven las políticas actuales, podría implicar el aplazamiento de una parte de los mayores hacia formas de hábitat intermedias entre las viviendas ordinarias y las residencias, como las residencias autónomas. El número de residentes autónomos, que actualmente asciende a algo más de 100.000, debería entonces multiplicarse por 1,5-2,5 en 2030 con relación a hoy, según las hipótesis de evolución del número de plazas en residencias elegidas. Las residencias se concentrarían entonces en la acogida de los mayores más dependientes. En una hipótesis más optimista, en la que la esperanza de vida sin pérdida de autonomía aumentaría tantos años como la esperanza de vida global, el mantenimiento del ritmo de apertura de nuevas plazas en residencias observado desde 2012 bastaría para mantener las prácticas actuales de entrada en institución de las personas mayores en pérdida de autonomía entre 2020 y 2050.

En el plano de la formación profesional, los profesionales que trabajan con las personas de edad son hoy numerosos y abarcan todas las disciplinas: profesionales de la salud, trabajadores sociales, profesionales de la ayuda a domicilio y de la medicina social. En las prácticas profesionales de estos últimos, la prevención es a menudo el pariente pobre y alejado del núcleo de la profesión, a imagen del lugar que ocupa la prevención en el sistema de salud francés.

El funcionamiento compartimentado entre profesionales se explica también por sistemas de información poco compatibles y que apenas se comunican entre sí. Además de la dificultad de la competencia de varios agentes a escalas de acción diferentes, esta falta de comunicación entre los sistemas de información perjudica la dirección, la valorización de las buenas prácticas, la evaluación de las acciones de prevención y la coherencia. Por consiguiente, sería conveniente:

- Incluir en la formación inicial de los profesionales (profesionales de la salud, trabajadores sociales y profesionales de la ayuda a domicilio) módulos sobre la prevención de la pérdida de autonomía y la detección de las vulnerabilidades de la vejez.

- Desarrollar los módulos de formación continua transversales que favorezcan una cultura común, compartida y abierta entre todos los profesionales.

En el plano operativo:

- Una heterogeneidad en la coordinación de las financiaciones según los departamentos e interpretaciones variables de las modalidades de financiación de las acciones.

- Desde los frenos técnicos y reglamentarios a la utilización de los concursos pagados por la CNSA.

- Un riesgo de “dispersión” y de sustitución de las financiaciones identificado en ausencia de una verdadera visión compartida de las políticas de prevención.

- En algunos departamentos, los miembros han tropezado con dificultades para encontrar su lugar en el mecanismo, presidido por el Consejo Departamental. 


\subsection{Retos, limitaciones y potencialidades de los modelos territoriales}

\section{a. El caso de la región de Nueva Aquitania y de Ipar Euskal Herria}

Nueva Aquitania era la región más envejecida de Francia en 2016. Para 2030, más de un tercio de la población tendría sesenta años o más. Como consecuencia del envejecimiento de la población, la región cuenta con 59.400 personas mayores dependientes. Sin embargo, la llegada de las generaciones de los baby boomers rejuvenecería a la población de mayores, lo que provocaría la casi estabilidad de la proporción de dependientes y la disminución de la de los más dependientes. Las mujeres, que viven más tiempo, se verían cada vez más afectadas, pero la diferencia entre mujeres y hombres se reduciría. En este contexto, aumentarían las necesidades de apoyo, tanto en el hogar como en instituciones. Los territorios se verían afectados de manera desigual y los mayores aumentos se registrarían en los departamentos costeros.

En primer lugar, el análisis, corroborado por el de la DREES, refleja a escala regional los límites señalados a escala nacional en los planos estructural, financiero y estratégico. Estos límites genéricos se precisan en función de los desafíos regionales:

- Limitaciones de los recursos humanos: las competencias iniciales de los profesionales varían mucho según los servicios, lo que da lugar a diferencias cualitativas significativas en cuanto a la consideración de las situaciones.

- Limitaciones ambientales: la inadecuación del entorno vital es uno de los límites de la atención a las personas de edad dependientes; esto se traduce en vivienda inadecuada, familias que no pueden o no quieren adaptarla, falta de recursos que impidan a veces adquirir suministros vinculados a la dependencia que no estén cubiertos por el plan de ayuda o los organismos de protección social/mutualidades, etc. Por otra parte, la malla territorial de la oferta de servicio es muy desigual en función de los departamentos y de la tensión ruralidad-urbanidad

- Las limitaciones de la creación de asociaciones y la coordinación: muy a menudo se tienen en cuenta las situaciones de dependencia en respuesta a los acontecimientos, en situaciones de emergencia, y a menudo no se preparan con suficiente antelación (salida del hospital, pero también entrada en EHPAD). La coordinación intra e interservicios no siempre es efectiva, sino que en ocasiones contribuye a la falta de legibilidad de la oferta de servicios y del acompañamiento.

Este estado de la situación pone de relieve algunas vías de reajuste. Se articulan en torno a los itinerarios de vida y de atención de las personas mayores dependientes, los medios de acción de los servicios, de coordinación y animación territorial y la ayuda a los cuidadores. Los cambios son los siguientes:

- Apoyar los itinerarios de vida y de cuidados de las personas mayores dependientes:

- Promover la evolución del dispositivo APA, en particular con un aumento de los planes de ayuda para la dependencia aguda.

- Ampliar la oferta de atención en las zonas deficientes.

- Ampliar los mecanismos de prevención de la degradación de las personas de edad.

- Adaptar los medios de acción de los servicios en términos de prácticas y de financiación para responder mejor a la dependencia:

- Despliegue de recursos humanos suficientes para una mejor calidad del acompañamiento.

- Despliegue de tiempo de apoyo a equipos más grandes para prevenir y limitar el desgaste profesional.

- Reforzar la coordinación y la animación territorial:

- Promoviendo la difusión de herramientas de comunicación compartidas que permitan intercambios más eficaces.

- Mediante la difusión de información clara, para aumentar la visibilidad acerca del conjunto de dispositivos e intervinientes, sus roles y limitaciones.

- Desarrollar la ayuda a los cuidadores:

- Favoreciendo "fórmulas de alivio" (con ayudas financieras para acceder a ellas).

- Promoviendo su acompañamiento directo.

Estos desafíos, limitaciones y perspectivas a escala nacional (estructural, financiera, estratégica, formativa y operativa) y regional (vinculadas a los límites en términos de recursos humanos, de toma en consideración y de estructuración del medio ambiente y de desarrollo de las asociaciones y de la coordinación) se encuentran también, en mayor o menor grado, a escala de Ipar Euskal Herria.

Así, las experiencias en los territorios de Ipar Euskal Herria plantean cuestiones en torno a:

- El lugar de la persona en su bienestar.

- Los mensajes de prevención accesibles a todos.

- Las acciones prioritarias en prevención.

- La oferta territorial de proximidad y la coordinación de los actores.

- La formación de los profesionales.

- La evaluación de las acciones y la mejora de los conocimientos.

En concreto, todos los territorios del País Vasco se ven afectados por el envejecimiento de la población y, en particular, las zonas rurales que ya parecen estar en tensión en términos de servicios, formas de acompañamiento y atención. El apoyo 
a la dependencia de una población cada vez más numerosa es un reto territorial de primer orden.

Tres cuestiones cardinales subyacen a la configuración de los territorios de Ipar Euskal Herria:

- Reto 1. El envejecimiento de la población en Ipar Euskal Herria requiere un acompañamiento creciente de las personas dependientes, en particular para el mantenimiento en el domicilio. Este reto debe vincularse con el de la prevención de la pérdida de autonomía y la lucha contra el aislamiento. El apoyo a las personas mayores dependientes se ejerce:

- Por la solidaridad familiar a través de la ayuda de familiares, ya sea por una solidaridad colectiva financiera (APA) o por la acogida en los EHPAD. El País Vasco interior (Baxe Nafarroa y Zuberoa) parece cubierto por las residencias, y dispone de alternativas como la acogida de día itinerante y la residencia autónoma. Sin embargo, en el departamento, las tasas de ocupación son actualmente de alrededor del 97\%-98\% para las residencias, alrededor del $95 \%$ para las residencias autonómicas y del 60\%-70\% para las recepciones diurnas (tasa variable según las recepciones diurnas).

- Mediante el desarrollo de actividades adaptadas, las visitas, las comidas, los sistemas de alerta, la robótica, etc. Desde un punto de vista social y cultural, el envejecimiento se traducirá probablemente en cambios en las prácticas de consumo, en el ámbito del ocio y de las necesidades de servicio (salud, transportes, comunicación, etc.).

- Reto 2. El riesgo de agotamiento y aislamiento se relaciona con la dependencia en el hogar y el perfil de los cuidadores familiares. Han surgido algunas alternativas a través del desarrollo de consultas de ayuda a los cuidadores familiares o profesionales como puede proponer el Equipo Móvil de Orientación Geriátrica (EMOG) del Centro Hospitalario Costa Vasca, o de descanso: acogida de día, acogida familiar, alojamiento temporal, etc. Parece necesario reforzar las ayudas técnicas o las soluciones de descanso para los cuidadores.

El domicilio parece ser el lugar de vida preferido de las personas de edad en comparación con las residencias. Sin embargo, vivir solo complica la posibilidad de permanencia en el hogar, sobre todo cuando se conjuga con la dependencia. En particular, se plantea la cuestión de la adaptación de la vivienda, la movilidad o la accesibilidad a los servicios.

- Reto 3. La profesionalización del sector de apoyo a las personas de edad avanzada que pueda responder al aumento de la población muy anciana que vive sola. Ya se ha iniciado un trabajo que debe reforzarse en torno al atractivo entre los jóvenes de los oficios de acompañamiento de las personas de edad, con el fin de hacer frente a la tensión en los servicios a domicilio, con una demanda cada vez mayor y una carencia de personal para responder a ello.

En vista de lo que está en juego, habría que investigar sobre varias vías:

- La necesidad de apoyar los itinerarios de vida y de cuidados de las personas mayores dependientes para prevenir mejor los efectos negativos del envejecimiento en cada una de sus etapas. La prevención de la pérdida de autonomía debe contemplarse en un enfoque holístico que tenga en cuenta los aspectos sanitarios, sociales, medico-sociales y medioambientales, con un enfoque transversal que implique al conjunto de los agentes públicos. El enfoque de la prevención debe basarse en un modelo participativo que implique más a los beneficiarios. No culpar ni estigmatizar a la persona es un requisito previo.

- La urgencia de movilizar los medios de acción de los servicios en términos de prácticas y de financiación para responder mejor a los desafíos multidimensionales de la dependencia. Es necesario que los recursos sean tanto más cuantitativos como más eficientes. Para ser más atractivos, el sector y los oficios de la dependencia hacia las personas mayores deben hacerse más atractivos en términos de condiciones de trabajo y de formación continua.

- La necesidad de que la coordinación y la animación territorial se refuercen y se clarifiquen en términos de complementariedad y de alternativa.

- La urgencia de desarrollar y estructurar la ayuda a los cuidadores de manera que se justifique su implicación y se les ofrezca la posibilidad de descansar, sin que ello perjudique a las personas mayores dependientes para las que están contratadas, ni que esto les perjudique a ellas mismas.

\section{b. El caso de la Comunidad Foral Navarra}

El sistema público de servicios sociales y la atención a las situaciones de dependencia y cuidados en Navarra han vivido avances positivos en la última década, sobre todo en materia de reconocimiento de derechos y extensión de sus servicios. Las últimas reformas en la cartera y en la reorganización de la atención primaria en Navarra han implicado grandes esfuerzos que han contribuido a un mayor desarrollo del sistema.

En relación con las potencialidades, cabe señalar que Navarra tiene un marco legislativo fuerte y avanzado en materia de atención a la dependencia. Cuenta con una cobertura de servicios reseñable, ha demostrado agilidad en los procesos de reconocimiento 
de las situaciones de dependencia y ha dado pasos importantes en la atención sociosanitaria, destacando la escala de valoración social de la dependencia, los pasos hacia la historia social única y la implementación de experiencias piloto de referencia. También presenta un nivel de gasto público elevado y amplios equipos de atención. Por último, cuenta con fuentes de datos disponibles que permiten medir el avance o retroceso del sistema. Estos avances conviven también con algunas limitaciones:

- Una estructura rígida e insuficiente: a pesar del incremento de financiación, las nuevas necesidades de cuidado y dependencia presentan unos recursos humanos y económicos insuficientes. No obstante, esta no es su principal limitación, pues es manifiesta la rigidez del propio sistema. Quedan barreras importantes por superar en materia de coordinación horizontal entre los sistemas sociales y sanitarios de atención a las personas. A pesar de buscar un modelo descentralizado flexible, su respuesta no ha sido tan ágil como cabía esperar, por lo que el modelo todavía experimenta dificultades para proveer atenciones más flexibles.

- La falta de adecuación del modelo a necesidades emergentes: la rigidez del sistema afecta a la adaptación y ajuste de la atención a medida que se detectan nuevos riesgos sociales. La disposición estructurada y formal impide acceder a necesidades localizadas, como los cuidados paliativos, de larga duración y aislamiento social que exigen mayor intensidad, flexibilidad y personalización en la atención. En el caso de la atención domiciliaria, cuyo recurso presenta una cobertura razonable, mantiene también algunas dificultades en intensidad y rigidez de horarios que pueden limitar la atención a personas con ausencia de redes, baja capacidad económica para complementar con otro recurso, o ausencia de otras formas de cuidado en algunas zonas rurales, donde la oferta de servicios es mucho más reducida.

- La escasa vinculación con el entorno comunitario: si bien el conjunto de servicios ofertados buscan en su filosofía cuidar en el entorno más cercano, presentan limitaciones en su articulación comunitaria. Pese a que muchos de los recursos como la atención diurna y la atención domiciliaria se ubican en el entorno de las personas en el hogar, su atención presenta en la práctica escasa vinculación entre el cuidado prestado y el entorno comunitario. En este sentido, resulta clave la incorporación de alianzas comunitarias que refuercen la relación con el medio (Pinzón et al., 2016).

- Una atención preventiva limitada: a pesar de contar con algunos recursos de mantenimiento en el entorno, la capacidad de los servicios sociales para desarrollar estrategias de prevención y promoción de la autonomía es reducida y cuenta con un desarrollo más limitado. En la propia cartera tan solo se reconocen mediante una línea de subvención a la participación de personas mayores, que ni siquiera está recogida como prestación garantizada. En el ámbito de la atención pública, destacan las "jubilotecas" como espacios de envejecimiento activo y participación, u otros del Tercer Sector como el espacio activo de Cruz Roja. No obstante, la mayoría de los recursos destinados se orientan más a la atención a la dependencia que a la promoción de la autonomía.

- La fragmentación administrativa y diversidad territorial: como se ha podido comprobar a lo largo de todo el texto, la fragmentación administrativa implica una gran complejidad en la atención desde el modelo de cuidados público. Si bien buena parte de los recursos son diseñados y financiados por los gobiernos regionales, las entidades locales tienen la capacidad de desarrollar otros como el SAD. Su resultado implica una fuerte diversidad de atención ya que pueden presentar diversos criterios de accesibilidad, oferta y precios. Teniendo en cuenta el conjunto de recursos y las diferentes necesidades de cuidados en algunas zonas territoriales, ello da lugar a algunas desigualdades entre la oferta y la demanda de cuidados, así como de otras necesidades vinculadas como el transporte en las zonas más aisladas.

\section{c. El caso de la Comunidad Autónoma del País Vasco}

Muchos de los retos que se plantean en el caso de la CAV han sido ya planteados para Ipar Euskal Herria y la Comunidad Foral Navarra. En todo caso, resumidamente, los principales retos que tiene el sistema vasco de atención a las personas con dependencia son los siguientes:

- La necesidad de impulsar la atención de las personas dependientes en el domicilio y de revertir la pirámide de atención, reforzando el cuidado profesional y apoyando al mismo tiempo el cuidado informal. Como en otros territorios, el modelo de atención a las personas mayores dependientes está en Euskadi todavía excesivamente basado en el apoyo residencial e institucional. El apoyo que reciben las personas que residen en sus domicilios está todavía insuficientemente desarrollado, tanto desde el punto de vista de la cobertura como de la intensidad. Reforzar el apoyo en el domicilio requiere establecer programas reforzados de gestión de casos que permitan coordinar el conjunto de los servicios sociales y sanitarios que reciben las personas en su domicilio, $y$, sobre todo, flexibilizar, diversificar, enriquecer e intensificar los servicios de asistencia domiciliaria

${ }_{5}^{5}$ Algunas de estas orientaciones coinciden, en lo esencial, con las que se plantean en el borrador de la evaluación del I Plan Estratégico de Servicios Sociales de la CAV, que apuesta por invertir la pirámide de atención, impulsando la atención, primaria y secundaria, en la comunidad; promover un nuevo equilibrio entre el cuidado institucional y familiar, en favor del primero; y transformar el modelo de centros residenciales y servicios de alojamiento. 
y facilitar el acceso a las adaptaciones domésticas y las ayudas técnicas que permitan hacer de la vivienda ordinaria el centro de la atención social.

- En ese marco, uno de los retos del sistema vasco de servicios sociales se refiere a la mejora de los servicios prestados a las personas cuidadoras. En ese sentido, se han dado pasos importantes para la elaboración de una estrategia sociosanitaria, de carácter integral, de apoyo a las personas cuidadoras, que sin duda contribuirá a la mejora de los servicios que se ofrecen a las personas que prestan cuidados.

- Es también necesario, como se señala en el borrador de la evaluación del I Plan Estratégico de Servicios Sociales de la CAV, impulsar iniciativas de promoción de la autonomía personal y prevención de la dependencia, así como acelerar el proceso de transformación digital en la provisión de servicios.

- En lo que se refiere al acceso a los servicios, es necesario reflexionar en Euskadi sobre el papel de las prestaciones económicas que permiten acceder a servicios de titularidad privada, como la prestación económica de asistencia personal (PEAP) o la prestación económica vinculada al servicio (PEVS), como ocurre en Francia ${ }^{6}$. Si bien la normativa vigente en la CAV plantea de forma muy restrictiva estas prestaciones, y si bien el recurso a este tipo de cheques-servicio puede contribuir a debilitar el concepto de responsabilidad pública, no debe dejar de tenerse en cuenta que el acceso a los servicios sociales mediante prestaciones económicas se ha ido extendiendo en Europa, entre otras razones, debido a que permiten una mayor autonomía, control y capacidad de elección a las personas usuarias. Hay ámbitos en Euskadi - como el de la atención domiciliaria-que probablemente funcionarían mejor si se fomentara una mayor diversificación de las empresas proveedoras y la posibilidad de que sean las personas usuarias, y no la Administración, quien contrate y defina la prestación del servicio. Este cambio exigiría, sin embargo, que las Administraciones reforzaran sus capacidades en cuanto a información y orientación a los usuarios, así como en cuanto a supervisión y evaluación de la atención, y requeriría en cualquier caso una primera aproximación experimental.

- Otro de los retos del modelo vasco de servicios sociales - aunque no sea exclusivo de los servicios sociales de la CAV - se refiere al impulso de un nuevo modelo de atención a la dependencia más personalizado y más flexible, más comunitario y mejor adaptado a las necesidades y a las expectativas de las personas usuarias. Este cambio de modelo pasa por una progresiva adaptación arquitectónica y ambiental de los centros residenciales, el impulso de las fórmulas

${ }^{6}$ También Navarra ha desarrollado una prestación de este tipo para el acceso a los servicios de asistencia domiciliaria. de alojamiento alternativo (apartamentos tutelados y viviendas comunitarias), la adaptación de las ratios y perfiles de atención, y el impulso de metodologías de intervención que verdaderamente pongan en el centro la autonomía de las personas usuarias. La próxima revisión del decreto que regula las condiciones de los centros residenciales para personas mayores permitirá sin duda avanzar en esa línea.

- Los datos que se han recogido en este informe ponen de manifiesto en qué medida el personal ocupado en el ámbito de los servicios sociales y, más concretamente, el personal ocupado en el ámbito de los servicios sociales de atención a la dependencia, no ha dejado de crecer en la CAV en los últimos años. Los datos recogidos también ponen de manifiesto, sin embargo, que la tasa de ocupación en el sector podría ser mayor si se acercara a la que se registra en Ipar Euskal Herria y en la mayor parte de los países de Europa, y que existe por tanto un potencial importante de creación de empleo en el sector.

Por otro lado, es importante tomar medidas relacionadas con la mejora de las condiciones laborales en el sector de los cuidados, teniendo en cuenta la diversidad de situaciones existentes en función del territorio histórico, la titularidad de los centros o los perfiles profesionales. Efectivamente, si algo caracteriza las condiciones laborales en el sector de los cuidados, es la desigualdad entre un sector de trabajadores/as con condiciones laborales razonablemente buenas y otro sector de trabajadores/as que trabajan en condiciones laborales muy precarias. Si bien no puede olvidarse que las condiciones laborales en el sector de los servicios sociales son en la CAV mucho mejores que las que se registran en otras comunidades autónomas, y que la mejora de sus remuneraciones ha sido superior a la que se ha registrado para el conjunto de la economía, es evidente que la adecuación de las condiciones laborales - tanto en lo que se refiere a la remuneración como en lo que se refiere a las posibilidades de formación, la supervisión profesional y la prevención de los riesgos laborales- es una de las asignaturas pendientes de los servicios sociales vascos. En ese contexto, la atención debería ponerse en los sectores más desprotegidos, como el de las mujeres -a menudo extranjeras- que trabajan como internas en los domicilios de las personas que atienden.

- La cuestión de las condiciones laborales está estrechamente relacionada con la sostenibilidad económica del sistema y, por tanto, con los costes de los servicios y con su financiación. En lo que se refiere al gasto destinado a los servicios vinculados al envejecimiento, sería conveniente combinar la mejora de las coberturas con la mejora de las ratios de atención y la mejora de las condiciones laborales. Es necesario crear más plazas, atender mejor a las personas ya atendidas y remunerar mejor a las personas profesionales, sabiendo en cualquier caso que los tres objetivos 
pueden no ser igualmente prioritarios - dependiendo de la situación en cada territorioy que avanzar de forma muy decidida en un sentido puede impedir avanzar suficientemente en otro, salvo que la disponibilidad presupuestaria sea ilimitada.

Desde el punto de vista de la financiación de los servicios de atención a la dependencia, la experiencia francesa podría resultar de interés en la CAV: en primer lugar, sería conveniente reflexionar sobre la posibilidad de establecer sistemas de financiación finalistas, como cotizaciones o impuestos específicos, tal y como se hizo en su momento en el Estado francés ${ }^{7}$; en segundo lugar, es imprescindible consolidar, clarificar y reforzar la participación financiera de otros sistemas -especialmente el de saluden la financiación de los servicios sociales y, específicamente, de los servicios residenciales; finalmente, sería conveniente revisar el sistema de participación económica de las personas usuarias, tendiendo - como establece la Ley de Dependencia y aprovechando la experiencia francesa- hacia modelos de triple tarificación, que diferencie el tratamiento de los gastos hoteleros y de los gastos derivados de la atención a la dependencia. Es posible que un cambio de esas características no implique una reducción de las tasas medias de copago en Euskadi, pero traería consigo sin duda una mayor transparencia y una mayor racionalidad en la financiación de los servicios residenciales.

- Probablemente, el principal reto de los servicios sociales vascos se relaciona con su ordenación territorial y su arquitectura institucional. Como se ha explicado previamente, las competencias respecto a la regulación, la planificación, la financiación y la gestión de los servicios sociales están repartidas entre el Gobierno Vasco, las diputaciones y los ayuntamientos, a los que se ha encomendado -independientemente de su tamaño- la provisión de una serie de servicios esenciales en el marco de un modelo comunitario y preventivo de servicios sociales. Este modelo descentralizado y desconcentrado responde a la trayectoria histórica de los servicios sociales y permite seguramente una buena adaptación a las características de cada territorio; genera también sin embargo problemas importantes, relacionados con la fragmentación de los agentes, las desigualdades de la ciudadanía en el acceso a los derechos sociales, el excesivo peso de la autonomía local y foral sobre el funcionamiento del sistema, las dificultades para el liderazgo o los obstáculos a la continuidad de la atención (Arrieta, 2019).
Para hacer frente a esas dificultades -además de reforzar de las herramientas comunes que prevé la Ley de Servicios Sociales ${ }^{8}$ y sin necesidad de modificarla- sería conveniente avanzar hacia el refuerzo de estructuras comarcales de servicios sociales, que, como ocurre con las organizaciones sanitarias integradas en el caso de la salud, asumieran de forma conjunta la prestación de servicios de atención primaria y secundaria. En ese sentido, podría ser aconsejable tender hacia una cierta difuminación de esos dos niveles de atención y, sobre todo, hacia una atribución más flexible de las responsabilidades sobre cada tipo de servicio a cada administración, en función de las características específicas de cada territorio y mediante herramientas que en la actualidad ya existen, como los consorcios interadministrativos de servicios.

- El reto del espacio sociosanitario. La pandemia de la covid-19 ha puesto de manifiesto, por otra parte, en qué medida es necesario articular mejor en Euskadi el espacio de coordinación sociosanitaria. En ese contexto, además de avanzar en los proyectos pendientes relacionados con la coordinación sociosanitaria, sería conveniente clarificar y mejorar la atención sanitaria que se presta a las personas usuarias de los centros residenciales para personas mayores, sobre la base de que corresponde al sistema de salud prestar una atención sanitaria de calidad a toda la ciudadanía, preferentemente desde los servicios de salud de nivel primario, independientemente de su lugar de residencia.

- El reto de la investigación, la evaluación y la garantía de la calidad. Como ya se ha señalado en otros documentos realizados en el marco de reflexión abierto por Eusko Ikaskuntza (Zalakain, 2019), dada la importancia que ha adquirido en los últimos años el sistema de servicios sociales, resulta necesario avanzar en el desarrollo de iniciativas orientadas a la innovación y la gestión del conocimiento en este ámbito. Frente al desarrollo técnico y profesional que han alcanzado otras ramas de las políticas sociales, como la educación o la salud, el sector de los servicios sociales carece aún de una estructura suficientemente articulada para la gestión del conocimiento y el impulso de la innovación. Desde ese punto de vista, es necesario articular en el ámbito de los servicios sociales centros e iniciativas solventes de $\mathrm{I}+\mathrm{D}+\mathrm{i}$ orientadas a identificar las necesidades sociales, garantizar la calidad de la atención, mejorar la formación de los y las profesionales, impulsar la práctica basada en la evidencia y evaluar el impacto de las políticas que se desarrollan en este ámbito.

${ }^{8}$ Cabe hacer referencia en ese sentido al Órgano Interinstitucional de Servicios Sociales, la Alta Inspección de Servicios Sociales, el Observatorio y el Sistema de Información de Servicios Sociales, el Consejo Vasco de Servicios Sociales o los propios equipos técnicos del departamento. 
AGUILAR-HENDRICKSON, M. (2020): “Long-term care in Spain: A reform failure or the regulation of a development path?", International Journal of Sociology and Social Policy, págs. 1-17.

- (2014) Apuntes para un replanteamiento de los servicios sociales en España, Madrid, Foessa.

ARARTEKO (2016): La situación de los servicios sociales municipales en la Comunidad Autónoma Vasca. Situación actual y propuestas de mejora, serie Informes Extraordinarios, Vitoria-Gasteiz, Ararteko.

ARRIETA, F. (2019): El archipiélago del bienestar. Los servicios sociales en el País Vasco, serie Investigación y Debate, nํ268, Madrid, Los Libros de la Catarata.

DÍAZ-VEIGA, P. y SANCHO, M. (2013): "Residencias, crisis y preferencias de las personas mayores”, Revista Española de Geriatría y Gerontología, vol. 48, nํㅜ 3, págs. 101-102.

LARBI, K. y ROY, D. (2019): “4 millions de seniors seraient en perte d'autonomie en 2050", Insee Première, no 1.767 .

LETURIA, M.; MENDIETA, A.; CARCAVILLA, A. y ZALAKAIN, J. (2019): Modelos de gestión de calidad en la atención a las personas con dependencia. Revisión internacional. Montevideo, Sistema Nacional Integrado de Cuidados.

MARTÍNEZ, T.; DÍAZ-VEIGA, P.; SANCHO, M. y RODRÍGUEZ, P. (2014): Modelo de Atención Centrada en la Persona. Cuadernos prácticos, Vitoria, Departamento de Empleo y Políticas Sociales, Gobierno Vasco.
MARTÍNEZ-VIRTO, L. y HERMOSO HUMBERT, A. (en prensa): "Hacia un modelo público de cuidados en la comunidad", Revista Española de Sociología.

MARTÍNEZ VIRTO, L.; SÁNCHEZ SALMERÓN, V. (2019): "Regional inclusion policies in Spain: New approaches and keys to their effectiveness", Investigaciones Regionales - Journal of Regional Research, nํ4, págs. 17-28.

OBSERVATOIRE NATIONALE DU DOMICILE (2018): TarifAPA. Étude des réalités départementales, Fédération Française des Services à la Personne et de Proximité.

OBSERVATORIO DE LA REALIDAD SOCIAL (2020): III Informe sobre la dependencia en Navarra 2019, serie Informes Anuales del Observatorio, Pamplona, Departamento de Derechos Sociales del Gobierno de Navarra.

SIIS CENTRO DE DOCUMENTACIÓN Y ESTUDIOS (2020): "Algunas pistas para la mejora del sistema de atención a la dependencia en España", Zerbitzuan, no 72 , págs. 77-90, くhttps://doi. org/10.5569/1134-7147.72.06>.

ZALAKAIN, J. (2019): “Desigualdad, exclusión y cuidados en los territorios de Euskal Herria: retos, fortalezas, consensos, disensos y posibilidades de avance", en VV.AA., XVIII Congreso de Estudios Vascos El futuro que nos (re)une: Congreso del Centenario, Donostia-San Sebastián, Eusko Ikaskuntza-Sociedad de Estudios Vascos, págs. 465-480.

- (2017): “Atención a la dependencia en la UE: modelos, tendencias y retos", Revista Derecho Social y Empresa, no 8, págs. 19-39. 